\title{
REAL-TIME FULLY AUTOMATED RESTAURANT MANAGEMENT AND COMMUNICATION SYSTEM "RESTO"
}

\author{
Kshitija V Godse ${ }^{1}$, Venkatesh Devale ${ }^{2}$, Kaustubh Patkar ${ }^{3}$, Sourabh Pandharpatte ${ }^{4}$ \\ ${ }^{I}$ Dept. of Computer Engineering, SKNCOE, Savitribai Phule Pune University, Pune, India \\ ${ }^{2}$ Dept. of Computer Engineering, SKNCOE, Savitribai Phule Pune University, Pune, India \\ ${ }^{3}$ Dept. of Computer Engineering, SKNCOE, Savitribai Phule Pune University, Pune, India \\ ${ }^{4}$ Dept. of Computer Engineering, SKNCOE, Savitribai Phule Pune University, Pune, India
}

\begin{abstract}
Existing restaurant systems are partially automated. We have developed a fully automated restaurant management and communication system. This paper covers the partial automation that exists and focuses the details regarding how we have implemented full automation in management and communication for restaurants. It also covers technical aspects of web based application and android application and how they are clubbed together with their advantages and disadvantages. It also lights the future work that can be added on regarding android application to make it more user friendly.
\end{abstract}

Keywords - REST API, HTTP Client class, jdk, Java, Servlet, IP Address, Android Device, Web based application - ****

\section{INTRODUCTION}

The application we are building is named "RESTO Restaurant Management and Communication System".

The traditional restaurant service requires waiters to interact with customers directly before processing their orders. However, a high-quality recommendation service system would actively identify customers and their favorite meals and expenditure records. [1] Here we are going to develop a system that is an automation of all the existing systems available today. There will be an Android Device available that will take the order from the user with no service person required. The user will be able to see the image and all details like how the dish actually looks, what all health related benefits can be achieved so that the customers who are health conscious with their respective health can be benefitted. The intention behind this project is bringing the innovation in restaurant processes. We have developed a system which handles this partial automation by giving the tab into customers hand and displaying him an e-menu card. Also the billing process will be processed through device whenever the customer wants to. Here the inventory is going to be maintained with a daily basis update to the system. The manager is going to play very crucial role in inventory, human resource, kitchen order table events online billing system, etc. We have focused a lot on giving customer full rights' right from order to getting the bill whenever he wants that too without intervention of service person or manager, wherein our idea of automation comes in and plays a vital role. With this manager can handle his work without a single paper and pen. Like he will be able to get a display of all the employees from various departments he has within his restaurant and can handle the human resource quite well. Then he can look into the details of various reports that will be generated. He can also see the history of various purchases he has made regarding the inventory like crockery and cutlery, Vegetable stock, prepared and other ingredients, their respective quantities. Thus we are trying to establish a real-time, fully automated restaurant management and communication system.

\section{BACKGROUND}

Existing restaurant management and communication systems are very limited in their part to play automated systems term.

In a study earlier [1], a preliminary experiment was conducted in a restaurant, and a questionnaire survey was administered to fifteen waiters and forty-five customers. The survey result was encouraging. They wanted some real-time automation. There are various restaurants that take the order from a tablet. The service person goes to the table, now the customer waits for the menu card to be placed on the table after that he decides the order and tells the service person whatever the order is. Now the service person makes the entries directly into the device and the order goes towards the chef manually. Now considering the order taking part, the automation that exists is just like they used to take it with pen and paper, wherein now they take it with the device. The multi-touchable restaurant management systems also have limitations like:

They usually require low resolution output of the monitor, can produce activation without touching the screen and the cost to produce the special Infrared bezel for touch screens is very high [5]. So from our side, we say this is a very nice automation, but a highly partial one if considered restaurant communication and management system as a whole. Also, apart from this we see that whatever the bill is generated is given to customer through service person and not on phone or email. Thus again the partial automation comes into play. When the customer pays the bill, the amount due is 
calculated by the cashier [1]. Although this procedure is simple, it may significantly increase the workload of waiters and even cause errors in meal ordering or in prioritizing customers, especially when the number of customers suddenly increases during busy hours, which can seriously degrade the overall service quality [1]. Now this is about the customer side. Let's see the manager side; the inventory handled is not at all under one roof. Like let's say, considering inventory there are various aspects of it like crockery and cutlery, vegetables, various types of ready and other ingredients. So speaking about handling of all this is done manually, wherein paper and pen comes and thus this is again a partial automation. It lacks real time feedback between restaurant owner and customers [4]. A number of PDAs are to be prepared to serve the number of customers during peak hours.

Thus increasing the restaurant expenditures [4]. So considering all these partial automations we are trying to club all these automations under one roof of an idea to develop a real-time fully automated restaurant management and communication system.

\section{COMPARISON BETWEEN SYSTEMS}

\begin{tabular}{|l|l|l|l|}
\hline $\begin{array}{l}\text { Sr. } \\
\text { No. }\end{array}$ & Characteristics & $\begin{array}{l}\text { Existing } \\
\text { Systems }\end{array}$ & $\begin{array}{l}\text { Proposed } \\
\text { System }\end{array}$ \\
\hline 1 & $\begin{array}{l}\text { Integration of Web } \\
\text { based application \& } \\
\text { Android application }\end{array}$ & NO & YES \\
\hline 2 & $\begin{array}{l}\text { Maintaining Inventory } \\
\text { Records in web based } \\
\text { application }\end{array}$ & NO & YES \\
\hline 3 & $\begin{array}{l}\text { Real-time Database } \\
\text { Management }\end{array}$ & NO & YES \\
\hline 4 & $\begin{array}{l}\text { E-Menu card } \\
\text { Real-time Stock alerts }\end{array}$ & NO & YES \\
\hline 5 & $\begin{array}{l}\text { Yhe customer will } \\
\text { handle the Android } \\
\text { device }\end{array}$ & NO & YES \\
\hline 7 & Real-time Feedback & YES & YES \\
\hline 8 & $\begin{array}{l}\text { Time based Statistical } \\
\text { Reports }\end{array}$ & NO & YES \\
\hline
\end{tabular}

Fig 1. Comparison between systems.

\section{TECHNICAL DESCRIPTION AND DESIGN}

\section{APPROACH}

\subsection{Technical Description}

\subsubsection{Android Application}

We have developed an android application in java with support API 21 that will be running on an android device. Now this device is given into the hands of the customer on a particular table. He will give the order from the e-menu card that is integrated in the android application. This order is placed towards the manger side. The only constraint we have implemented here is about the time after which the customer will not be able to cancel his order. Now whatever time he takes to finish after that particular time he can get the bill just on a tap on his device. The bill generated on the manager side will be displayed to customer and a message will be sent on his mobile no. which will be acquired by this app while taking his details. Customer can leave feedback after everything over.

Now this android app does reduce the interference of the service person to almost everything. Only the service will come to give the table no. and device for a customer that's it, after that everything will be handled by this application. This application is built to send data to web service running on manager side with the HTTP Client classes and methods. Also the data travels in the service on the IP configuration of the machine running the web service.

\subsubsection{Web Application}

The manager side is handled by this web application that is running on the managers Desktop. Now considering this side, it takes the details of whatever order or feedback got from the Android app through web service. This application handles the functionality of human resource management, customer relationship management, feedback management, and stock maintenance at run time, keeping track of inventory right from purchase to stock level alerts, also one can get history of everything including purchases through various vendors and same on the basis of reports generated on a timely basis.

This web service runs under the concept of REST API which we have implemented to get our data from android application over IP address. Also, we are implementing JSON object to hold data. JDatatable is also implemented here in order to give manager as a user a very user-friendly experience with a lot of functionalities such as add, update, delete and search. We have used Servlet, Java script, SQL Libraries for implementation.

\subsection{Design Approach}

This design gives an exploration about how we are implementing our aim with the help of android application and web application.

\subsubsection{Android Application}

1. Gets order from customer with the display of e-menu card.

2. Gives user time to bill his order when he finishes.

3. Sends the details to manager side through web service.

4. Also functionality of feedback, photo gallery.

\subsubsection{Database}

This stores the data from the android application into the database which is linked to the manager side running the web service. 


\subsubsection{Web Application}

Running on the manager side as a server it performs following tasks:-

1. Getting order and verifying stock.

2. Handling inventory aspects like checking available stock and accordingly raising alerts.

3. Generating reports on timely basis.

4. Handling human resource, vendor-purchase history, getting feedback for betterment.

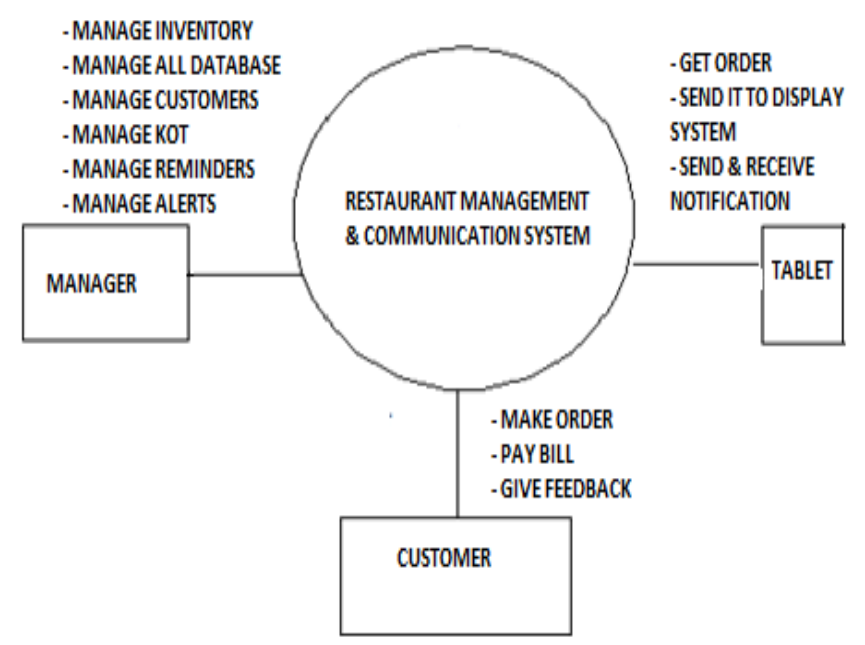

Fig 2. System Data Flow Diagram.

\section{SYSTEM ARCHITECTURE AND SPECIFICATIONS}

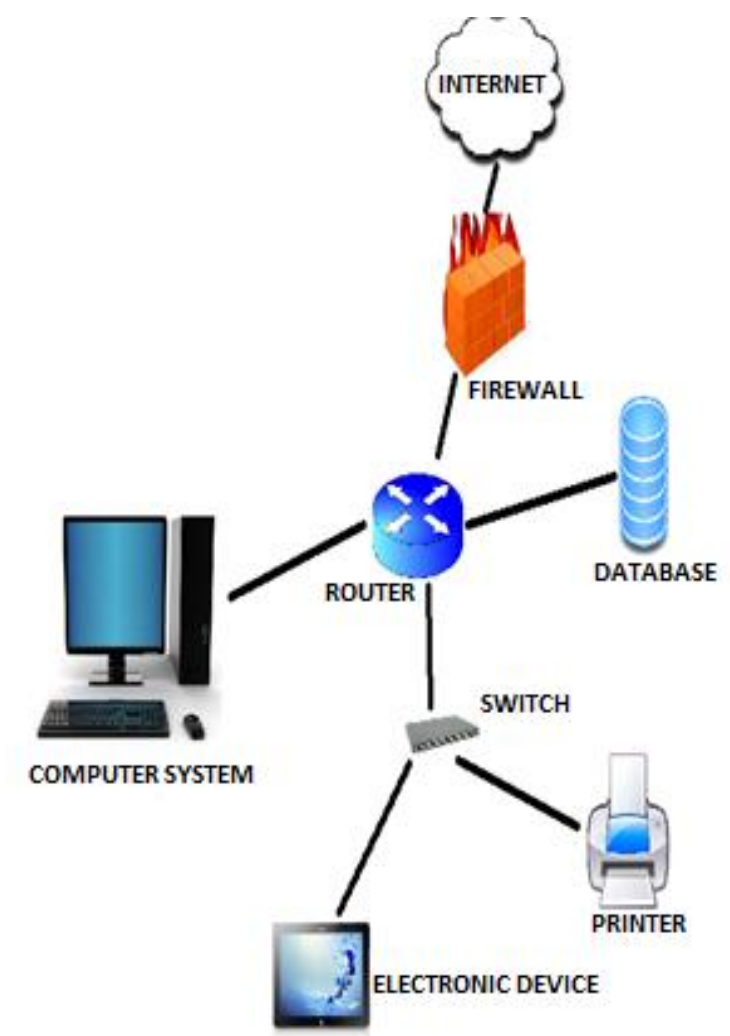

Fig 3. System Architecture.
Android application built in Eclipse Luna version with minimum API Level 8 and supports all devices running any android version till API level 21. Web application developed with the use of servlet, JavaScript in Eclipse Luna.

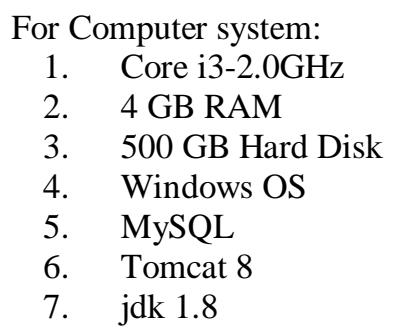

For Electronic Device:
1. Wi-Fi support
2. Internet access
3. Router
4. Android 4.4.0
5. Web Browser

\section{CONCLUSION AND FUTURE WORK}

The system that we have developed is quite a full automation but also open to get some real-time integration with some innovations.

The add-ons that can be integrated are:-

1. At present our system is limited to restaurant, customer that visit that particular restaurant can use it. But we are planning to develop it further to get order from remote locations online. Also the option for home delivery can be added on.

2. We can also give the customer a right to book the table and then he will be given with the specific time so that he can come to restaurant in that specific allotted time. With this, he may also get GPS enabled parking assistance on his way to restaurant.

\section{ACKNOWLEDGMENTS}

This work is completed under the guidance of Prof. A. A. Bhawarthi. We would also like to thank the reviewers for their suggestions to improve this paper.

\section{REFERENCES}

[1] Tan-Hsu Tan, Ching-Su Chang, Yung-Fu Chen, Yung-Fa Huang, Tsung-Yu Liu, "Developing an Intelligent e-Restaurant With a Menu Recommender for Customer-Centric Service", Systems, Man, and Cybernetics, Part C: Applications and Reviews, IEEE Transactions.

[2] Shweta Shashikant Tanpure, Priyanka R. Shidankar, Madhura M. Joshi, "Automated Food Ordering System with Real-TimeCustomer Feedback".InProceedings of theInternational Journal of Advanced Research inComputer Science and Software EngineeringVolume 3, Issue 2, February 2013 (ISSN: 2277 128X)Research PaperAvailable online at: www.ijarcsse.com 
[3] Chih-Yao Lo, Chun-Ta Lin, Chia-Lung Tsai, "Mobile Restaurant Information SystemIntegrating Reservation Navigating andParking Management". InProceedings of theInternational Journal of Engineering and Technology Vol.3 (2), 2011, (ISSN: 173-181). Chaochiao Township, Miaoli County, 36143 Taiwan.

[4] K. Kamarudin, et al., "The Applictaion of Wireless Food Ordering System", MASAUM Journal of Computing, vol. 1,pp. 178-184, 2009.

[5] J. Mustafa, et al., "Touch \& Dine : A multi-touchable dining system", UAEE International Journal of Computer Science and its Applications, vol 1, issue 1.ISSN 2250-376

[6] XU Hongzhen, et al, "Wireless Food Ordering System Based on Web-services", Second international Conference on Intelligent Computation Technology and Automation, 2009. 